\title{
Research on Human Resource Management in the Logistics Industry in the Context of Public Health Emergencies
}

\author{
Changli Lu, Wenshan Feng* \\ School of Economics and Management, Shanghai Maritime University, Shanghai, China \\ Email: *fwenshan@163.com
}

How to cite this paper: Lu, C. L., \& Feng, W. S. (2021). Research on Human Resource Management in the Logistics Industry in the Context of Public Health Emergencies. Open Journal of Business and Management, 9, 167-183.

https://doi.org/10.4236/ojbm.2021.91009

Received: November 15, 2020

Accepted: January 4, 2021

Published: January 7, 2021

Copyright $\odot 2021$ by author(s) and Scientific Research Publishing Inc. This work is licensed under the Creative Commons Attribution International License (CC BY 4.0). http://creativecommons.org/licenses/by/4.0/

\begin{abstract}
The COVID-19 outbreak has hit the logistics industry like never before. How to effectively cope with the challenges brought by public health emergencies has become an urgent problem for major logistics enterprises. As a labor-intensive industry, the human resource management of logistics enterprises has become an essential and important part of their operation and management process, which is directly related to the healthy, sustainable and stable development of logistics enterprises and the maximization of social and economic benefits at the lowest cost. Therefore, logistics enterprises must establish advanced concepts of human resource management and take reasonable and effective measures in combination with their own problems in this outbreak, so as to enhance their core competitiveness.
\end{abstract}

\section{Keywords}

Emergency Logistics, Public Health Emergencies, The Human Resources

\section{Introduction}

The 2020 COVID-19 is a double-edged sword for all enterprises: it breaks our inherent stable mode of survival, which makes people suffer a certain spiritual and material impact, and at the same time, it makes people soberly realize that they are always in a complex and changing environment, and the rule of "survival of the fittest" still applies, only the self! Iteration is the only way to move into the future. Since the occurrence of the new crown epidemic, the logistics enterprises actively and quickly take action to ensure that masks, protective clothing and other emergency supplies in place in a timely manner, good logistical support work, and made great contributions to the resolution of the crisis. 
However, while strengthening the construction of emergency logistics system and improving the supply chain management, the logistics enterprises seldom paid attention to the human resource management of emergency logistics. In the face of the crisis, the organizational structure began to be exposed, senior managers are full of worry and anxiety, at this time the human resources department to take the initiative to promote company change, so that the company through the systematic reengineering to survive and develop. As the main body and pillar of the emergency logistics, emergency logistics personnel can be efficient management often becomes the key to deal with sudden safety and health events. The current emergency logistics personnel team construction still exists a lot of problems, the need to continue to improve the development. How to build a professional and efficient emergency logistics talent team, become the logistics enterprises and even the whole society have to consider the important issue.

\section{Literature Review}

\subsection{Overview of Theories Related to Human Resources for Emergency Logistics in the Event of a Public Health and Safety Emergency}

\subsubsection{Public Health Security Emergencies}

As the name implies, a public safety and health emergency is an event that occurs suddenly and may endanger or may endanger the public health and safety of society. It mainly includes infectious disease epidemics, mass unexplained diseases, food safety and occupational hazards, animal epidemics, and other events that seriously affect public health and life safety.

According to the process, nature and mechanism of the occurrence of public emergencies, public emergencies are mainly divided into the following four categories: 1) natural disasters. They mainly include flood and drought disasters, meteorological disasters, earthquake disasters, geological disasters, marine disasters, biological disasters and forest and grassland fires. 2) Accidental disasters. Mainly including all kinds of safety accidents of industrial, mining, commercial and trading enterprises, transportation accidents, accidents of public facilities and equipment, environmental pollution and ecological damage, and so on. 3) Public health events. Mainly including infectious disease epidemic, mass unexplained diseases, food safety and occupational hazards, animal epidemic, and other events that seriously affect public health and life safety. 4) Social security events. These mainly include terrorist attacks, economic security incidents and foreign-related emergencies. Various types of public emergencies are generally classified into four levels according to their nature, severity, controllability and scope of influence: Level I (particularly significant), Level II (major), Level III (major) and Level IV (general).

\subsubsection{Emergency Logistics}

As a special kind of logistics activity, emergency logistics also has the utility of the most common materials transport of ordinary logistics. However, compared 
with ordinary logistics, emergency logistics maximizes the efficiency of resource utilization and also ensures the economic interests of the enterprise, regardless of the return of interests, and requires the transportation of emergency materials in the shortest time in the country or even the whole world, and provides strong logistical support for the sudden public safety and health events. Emergency logistics often has the following characteristics.

1) Unpredictability. As public health emergencies are highly unpredictable, and their time, location, scale, and impact are difficult to predict, the emergency logistics generated in response to public safety and health emergencies are also unpredictable.

2) Diversity of needs. Public safety and health emergencies include both natural disasters and man-made disasters, different types of emergencies of different scales, different degrees of impact, the need for materials are also different, resulting in the occurrence of disasters after the variety of materials needed, the number of different, logistics companies need to be based on the diversity of material needs of the material diversity of deployment.

3) Weak economy. The safety of people's lives and property must come first in all work under the conditions of public safety and health in an emergency. The logistics enterprises must take up their social responsibility, regardless of the cost and economic benefits, and send emergency supplies to the place of occurrence with the fastest speed. Emergency logistics emphasizes more on the speed and efficiency in the process of material deployment and transportation, thus weakening the economy of logistics.

4) Time urgency. After a sudden public safety and health event, time is everything, and emergency logistics need to overcome difficulties such as long distances and roadblocks to deliver supplies in a timely manner, which has a great test on the response time of emergency logistics activities.

5) Diversity of subjects. The handling of public safety and health emergencies requires the coordinated participation and cooperation of all units, departments and regions, and it is difficult for one party to provide the required human and material resources. Therefore, the operation and scheduling of emergency logistics in case of an emergency requires not only the efforts of the government and logistics enterprises, but also the coordination and cooperation of all units and departments at all levels, so it is subjective pluralism.

\subsubsection{Human Resource Management Theory}

Human Resource Management (HRM) refers to the rational allocation of human resources according to the needs of the organization's survival and development, and the systematic implementation of a series of work such as recruitment, training, use, assessment, motivation, adjustment and so on, to stimulate the work potential of employees, according to the requirements of the organization's development strategy. Improve the quality of the staff themselves, mobilize the enthusiasm of the staff, thereby enhancing the efficiency of work and ensure that the enterprise to achieve the set goals. 
Human Resource Development (HRD) is a management activity aimed at improving the quality of human resource management. Domestic scholars of human resource development understanding of research vary. Scholar Song Xiaowu uses the economic point of view to describe human resource development, that is, the organization through investment to achieve the process of human capital appreciation. He believes that HRD is the use of existing resources and services to transform the training of the original human resources, so that they become human resources with a certain level of health, knowledge and social skills, and contribute to the achievement of organizational goals. Hu Chun believes that HRD is an activity to improve economic efficiency by improving the quality of human resources, i.e. using a variety of effective methods to fully explore the potential of human resources, adjust the structure of human resources, improve the quality of human resources, so as to maximize the use of material resources, and then maximize the economic benefits of all activities. Xiao Mingzheng believes that human resources development refers to an organized and purposeful learning activity, the purpose of which is to improve their own quality and work performance. It is also a formal education, vocational training and social enlightenment service for all personnel involved in the state and enterprises, including education, training, deployment, use and other processes (Gao, 2010).

\subsection{Overview of Research on Human Resources under Emergency Logistics}

In recent years, due to the "SARS" incident in 2003, the Wenchuan earthquake in 2008 and the recent global epidemic of Xinguan, the emergency management of public health emergencies has become a hot topic of discussion nationwide and even worldwide. In the face of disasters, countries, governments and enterprises have realized the importance of emergency logistics and the guarantee and supply of talents, and have made serious reflection on how to establish an efficient and orderly emergency logistics talents team. Scholars at home and abroad have also conducted a lot of research on this issue and achieved some results. The next section will summarize the current status of domestic and foreign research in emergency human resource management.

Currently, national and international scholars mainly study the construction of emergency human resource management systems by examining the basic concepts, operational processes, and components of emergency management systems. GBarb Osogki analyzes the two-stage planning framework for health emergency personnel in staffing plans, which focuses on the allocation of the corresponding emergency human resources by assessing the available emergency capabilities in an emergency. The assessment of rare emergency response capabilities focuses on the effectiveness and reliability of existing emergency response systems. According to Landesman, ordinary public safety emergencies can be managed by government agencies and human resources are allocated based on 
contingency plans. When a higher level emergency occurs or when an ordinary emergency is transformed into a higher level emergency, extraordinary procedure and specific authorities should be used to control the scheduling and management of human resources, primarily looking at the allocation, deployment, and training of emergency human resources to manage the capabilities. Richard C. Larson and Evel A. Ranc studied the management strategies of emergency human resource and made recommendations for improvement, suggesting the need to strengthen the information coordination capacity of emergency human resources management. For information sharing, information hardware and software resources should be allocated effectively.

Domestic scholars such as Zhao Chenggen's book "Research on Crisis Management Models in Foreign Large Cities" comprehensively analyzes the basic structure and operation of the whole-government, whole-society type integrated crisis management system in large cities of Western developed countries, and summarizes the experience from the practice in Europe and the United States, which is inspiring to the construction of emergency response personnel under the conditions of public safety and health emergencies in China. Two scholars, Xue Lan and Zhong Kaibin, argue that public safety and health emergencies have different types and impacts, and the government needs to take different emergency management measures, including emergency human resource management measures; Zhao Hong and Wang Liang make three suggestions for emergency human resource management in China through their study of the U.S. federal emergency plan. First, establish a permanent emergency organization at the central, local, and grassroots levels. Second, formulate emergency management related laws and regulations; and finally, establish a human resource management system for health emergencies. According to Wang Jun, the government should have the following powers, namely the temporary duty and power to stockpile emergency supplies and declare an emergency, the power to guide and supervise news reports on emergencies, the power to formulate and initiate emergency plans, the power to evaluate public safety and health emergencies themselves, and the power to supervise the emergency management process in real time. By studying the problems in responding to public safety and health emergencies in China and summarizing their experiences, Junchang Shan discusses how to establish and improve the emergency human resource management system for public health emergencies. Xie Jinqiang and others applied the competency quality model to the recruitment and selection, salary management and performance management of emergency logistics personnel, and attempted to establish high-level selection and evaluation criteria for emergency logistics personnel management. Zhang Ge thinks that the development of emergency logistics is very important to protect people's lives and property, so it is more important to strengthen the construction of emergency logistics talent team. Liu Zhongying and Zhang Jianhua researched and developed an intelligent and efficient human resources emergency management information system 
based on rule-based reasoning and case-based reasoning technology, which enhanced the coordination and communication ability of the emergency response team, the organization's emergency rescue ability, and further developed the informationization and intelligence of the emergency response team. Chen Jianming and Yang Jing analyzed the methods and ideas of emergency event classification from a systematic point of view, put forward the idea of dynamic classification and classification, and applied cluster analysis and discriminant analysis to the classification and classification of emergency events. Bao Ligang believes that under the new crown epidemic, logistics enterprises face serious human resource problems within. Enterprises should protect the legitimate rights and interests of employees in special periods, make reasonable arrangements for employees to return to work, implement flexible working hours and online employee training.

In general, the current domestic and foreign scholars are relatively lack of research on the human resource management of emergency logistics under public safety and health emergencies. Most of the scholars' research on emergency logistics focuses extensively on the management of emergency supplies and transportation, while ignoring the human resource management in the logistics and transportation process and the dynamic role of human beings in public safety and health emergencies.

\section{Research Design and Methods}

Based on the theories of public health emergencies, emergency logistics, and human resource management, and based on a large amount of solid theoretical data, this paper uses Jingdong as an example to analyze the current basic situation of China's emergency management human resources under the neo-crown epidemic, and based on this, it proposes practical measures to further improve the human resource management of health emergency in public health emergencies. Emergency logistics in the event of a health event provides some suggestions.

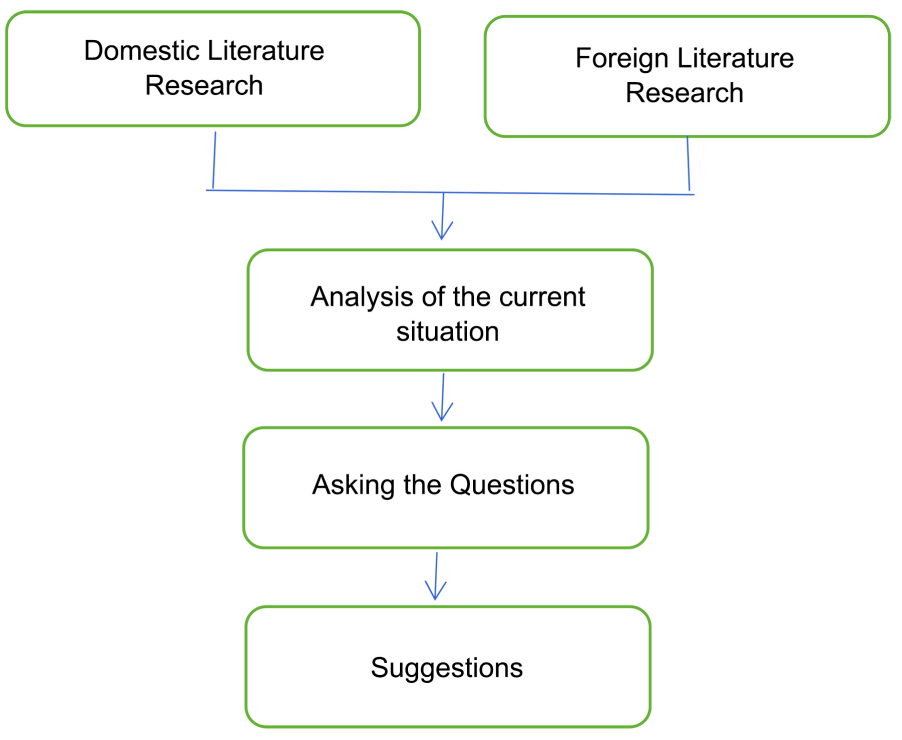


The research methods used in this paper are:

1) Literature Approach. This paper will summarize the theoretical and practical experiences on public health emergency response methods, emergency human resources, etc. by reviewing a large number of literature.

2) Comparative analysis method. It is a method of comparing two or more relevant and comparable data to reveal differences and contradictions. This paper briefly introduces the representative methods of emergency human resource management in Western countries and introduces the experiences of representative Western countries in emergency human resource management.

3) Case study method. The case study method is a research method that identifies a particular object of study, investigates and analyzes it to find out its characteristics and formation process. This paper takes Jingdong and FedEx as examples to analyze the human resource management measures of domestic logistics enterprises under the epidemic, in order to understand the current situation and problems of human resource management of logistics enterprises under public health emergencies.

\section{Human Resource Management Measures in the Logistics Industry in an Epidemic Situation}

During the new crown epidemic, a large number of logistics enterprises actively engaged in the fight against the epidemic, playing a leading and exemplary role. In order to accurately grasp the problems encountered by A-class logistics enterprises in the resumption of work, in February of this year, the China Federation of Logistics and Purchasing conducted a survey among the 546 A-class logistics enterprises. Before February of this year, 141 companies joined the epidemic prevention logistics services; early February, three companies joined the anti-epidemic activities; mid-February, 66 companies to participate in epidemic prevention services; as of the end of February, the number of companies involved in logistics epidemic prevention work increased by 30 . This has been illustrated in Figure 1. The survey also showed that more than $94 \%$ of the enterprises surveyed were willing and very willing to join the national emergency logistics service system. The timely delivery of all kinds of emergency supplies is a crucial part of the process of fighting epidemics under sudden public safety and health events, and the logistics enterprises play an irreplaceable role.

Most of the 546 Class A logistics companies surveyed returned to work in February. However, 21 percent of companies have yet to return to work. Of the 546 companies, 290 (53\%) resumed work in mid-February; 141 (26\%) resumed work in late February. Sixty-five firms (12 percent) are expected to resume work in early March. A small number of companies said they would delay their return to work, with four businesses expected to return to work by late March. The epidemic has had a significant impact on the efficiency of current emergency logistics, as employee attendance has not met expectations. Figure 2 illustrates the resumption of work of epidemic prevention logistics enterprises. 
According to the survey, as of February 24, 242 companies had an employee arrival rate of 70 percent or more, accounting for 44 percent; 109 companies had an employee arrival rate of 50 to 70 percent, accounting for 20 percent; 105 companies had an employee arrival rate of 30 to 50 percent, accounting for 19 percent; and 90 companies had an employee arrival rate of 30 percent or less (Henan Business Daily, 2020). Figure 3 shows the attendance rate of logistics employees under the epidemic situation.

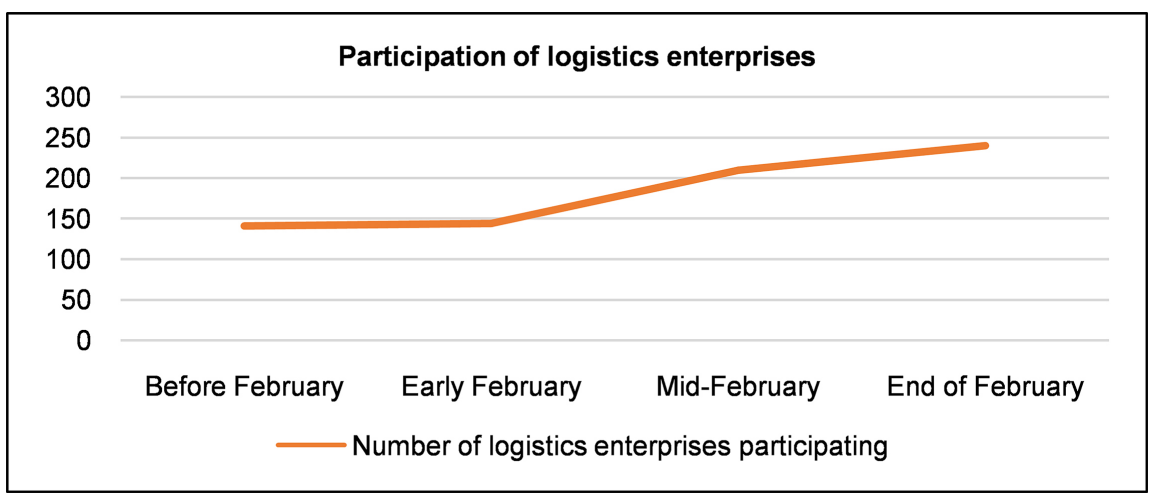

Figure 1. Participation of logistics enterprises. Source: China Federation of Logistics and Purchasing (http://www.chinawuliu.com.cn/).

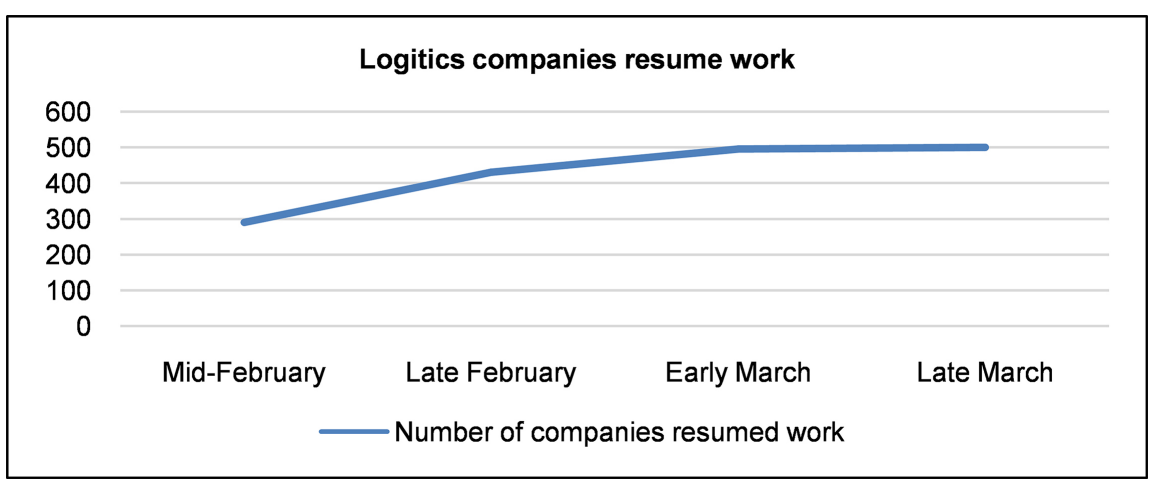

Figure 2. Logistics companies resumed work. Source: China Federation of Logistics and Purchasing (http://www.chinawuliu.com.cn/).

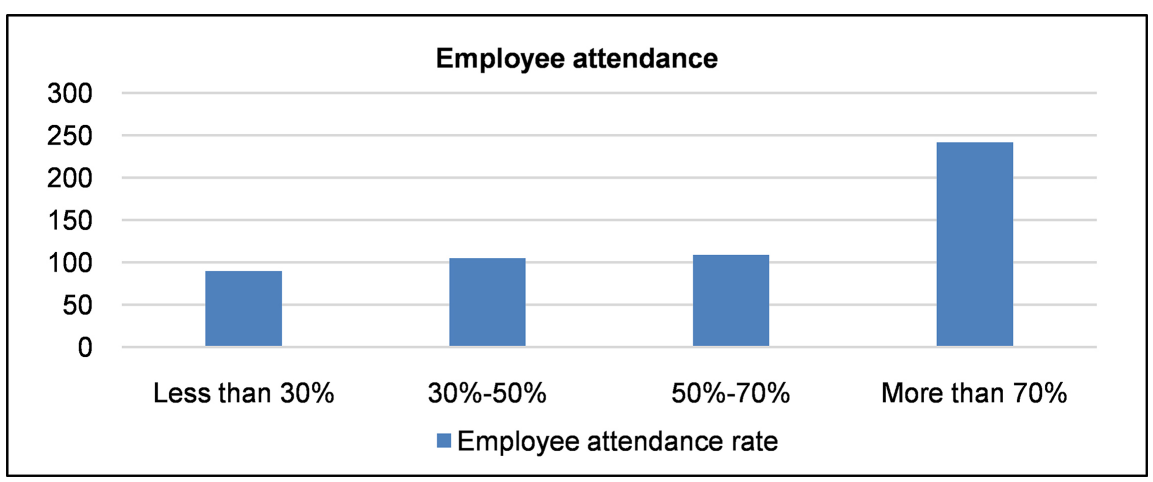

Figure 3. Employee attendance. Source: China Federation of Logistics and Purchasing (http://www.chinawuliu.com.cn/). 


\subsection{Analysis of Human Resource Management Measures in Logistics Private Enterprises under Epidemic Conditions}

Sudden outbreak of new coronary pneumonia, making the private logistics enterprises' ability to withstand crises and emergency response capacity to be tested. Since the outbreak of the epidemic, the private enterprises have set up epidemic prevention leading group, the company manager as the first person in charge of coordinating the relevant epidemic prevention work. The company actively ensures the resumption of work and production at the same time, also took the prevention and control measures. A survey by the National Bureau of Statistics shows that more than half of private logistics companies have taken measures to ensure the safety and health of their frontline employees by combining security and training.

In order to raise employees' awareness of epidemic prevention and protection, Jingdong, for example, actively organizes employees to learn about epidemic prevention and strengthens employees' personal hygiene and epidemic prevention initiatives. In order to protect the life safety of employees, the initiative to launch the epidemic prevention insurance for employees. Throughout the Spring Festival and the epidemic period, Jingdong Logistics has been insisting on normal operations. In order to protect the personal life safety of employees, the company continues to distribute emergency supplies such as masks, disinfectants, and thermometers within the company. The disinfection of all workplaces, restaurants, dormitories, old vehicles and equipment, as well as the disinfection of incoming and outgoing shipments, is carried out regularly. In addition, Jingdong Logistics strictly abides by the epidemic prevention and control policies of the local government and the community, establishes a routine inspection mechanism, conducts daily inspection and health monitoring for all frontline employees, and at the same time, conducts epidemic-related knowledge dissemination and prevention and control training, and strictly implements the government's epidemic prevention and control requirements. Jingdong Logistics has also purchased pneumonia insurance for all frontline employees to ensure their health and safety (Xi'an Daily, 2020).

Under the epidemic, the human resources department of Jingdong Logistics has carried out the following detailed work.

1) Establish an information registration system. Before returning to work, the human resources department will record and count the information of the employees returning to work, such as when they go to work, where they return from, whether they need to be quarantined, etc., in order to facilitate the subsequent work arrangements of the employees. After returning to work, the HR department will coordinate with the employees to record work logs, conduct self-examination and preventative control measures for the employees' physical condition, make dynamic monitoring reports, and send the above reports to the employees and the company management in a timely manner, according to the actual situation. 
2) Develop guidelines for returning to work. The human resources department makes a booklet of epidemic prevention and control methods, skills and knowledge and distributes it to every employee. Employees can carry them with them and consult them at any time. In addition, the human resources department has developed different epidemic prevention and control training programs based on the characteristics of different jobs.

3) Regular attention to employee health. For employees on the front line, the company provides them with protective equipment such as masks and alcohol, and conducts daily disinfection checks at regular intervals in order to ensure their safety.

For employees who have been infected with the new pneumonia, the company follows up on them in real time, pays close attention to their physical condition, and tries its best to provide them with medical assistance. In times of crisis, good employee care can improve the cohesion and centripetal force of employees, and thus promote corporate culture (Knowing, 2020).

Human resources departments are also working hard to maintain employment stability during special periods. In order to prevent and control neo-coronary pneumonia, governments at all levels have issued a series of documents on issues related to the time for returning to work, recognition of work-related injuries, recruitment methods, labour relations and the calculation and payment of overtime wages, which mainly set time limits for employees to return to work and spatial limits on the form of business operations, especially those of a crowd-intensive nature, such as internal staff training and external staff recruitment. Therefore, the human resources departments of enterprises actively take into account the local situation, during the epidemic prevention period, most of the offline business to online business, for example, offline job fairs to online recruitment and adopt the form of video interviews, offline training activities to online training; other offline activities that have been carried out can choose to postpone and postpone. At the same time, the Government will do a good job of dispatching employees to work and outsourcing, safeguarding the legitimate rights and interests of employees and promoting harmonious and stable labour relations.

\subsection{Analysis of Human Resource Management Measures of Foreign-Funded Logistics Enterprises in the Epidemic Situation}

After the outbreak of the epidemic, foreign invested enterprises have acted quickly and adopted "epidemic welfare" measures to provide different benefits for different types of employees in different positions and with different needs. For example, employees who could not return to work in time, front-line employees who lacked protective gear, and employees who chose to work online due to the epidemic. In addition, foreign-funded enterprises also actively provide psychological assistance to all employees, communicate with them in a 
timely manner, understand their needs and stress and reassure them to enhance their sense of security and trust.

It is widely recognized that providing employees with flexible working hours and working methods is a top priority for foreign companies. In order to ensure the safety of their employees, many foreign-owned companies are working online as the first option for returning to work, with flexible working and leave systems and regular face-to-face video conferences to follow up on progress. In fact, a large number of foreign companies have already implemented online workstations before, and the outbreak has caused them to review their online work processes and make continuous improvements to improve their online work efficiency. The HR department is the people management department of the company, coordinating the flexible working arrangements between management and staff, as well as the practical experience gained during this particular period. New working time and space arrangements have been developed, and new communication and reporting mechanisms have been established to ensure the productivity of the company's employees, thus improving the practicality of the online office.

Take FedEx as an example, it will be able to practice the content of online services, laying the foundation for the future to build a comprehensive online service process covering supply and demand docking, business negotiations, contract signing, financial payments, service implementation, service evaluation, relationship maintenance, etc., forming a closed loop of online services, minimizing the need for offline services. For example, video conferencing is used to conduct preliminary business negotiation with customers, as well as work reporting and relationship maintenance; 24-hour online customer service is used to provide employees with many services such as inquiry, handling and change of five insurance, one insurance and personnel files, etc. In case of complications, manual customer service can be transferred to answer questions to reduce the need for on-site service. In the aftermath of the epidemic, we will summarize the experience and further enhance and improve the online service closed loop, promote the qualitative change of service mode, and prepare in advance for the next public emergency.

In terms of employee training, the traditional offline training program could not be implemented in this particular situation. The HR department started to adopt online training. In recent years, online training has been gaining recognition, and the outbreak has provided a unique opportunity for online training to develop. Online training can be flexible in terms of time, so that employees can be trained anytime, anywhere. Even if the epidemic is over, online training can still be a new way to train employees. The human resources department made different online employee training plans by analyzing the job characteristics of employees in different positions, making the training forms diverse (Jiang, 2007).

In the distribution business, foreign-funded logistics companies also attach 
great importance to customer experience and actively seek to establish new customer service models. For example, contactless express mode, "last mile" intelligent services, the establishment of self-carry cabinets, unmanned vehicle delivery and other methods to ensure the safety and health of both courier staff and customers.

\section{Problems Facing Human Resource Management in Logistics Enterprises under the Epidemic}

\subsection{Low Level of Information Management in Enterprises}

In terms of staffing, the human resources department of logistics enterprises usually gives priority to experience management, pays little attention to information management, and has not yet established a perfect human resources management information platform. Management easily relies on their own management experience and emotional thinking, the layout of job settings and business allocation often rely on the subjective analysis of human resources managers, and the lack of rational data analysis of individual employees' abilities. Logistics enterprises can hardly make full use of the emerging information and network technology for human resource management, which will reduce the functionality and effectiveness of enterprise management in the long run.

\subsection{Limited Quality and Mobility of Employees}

Compared with high-tech enterprises, logistics enterprises have a certain disadvantage in terms of the quality of employees, the overall quality of staff needs to be improved, the lack of specialization of managers, the rural areas are difficult to introduce excellent management personnel. Corporate front-line couriers are usually from the local rural areas, their low level of education, limited business skills, and poor stability, lack of awareness of the contract, more mobile. Employees overall show localized characteristics, exclusive, lack of learning and innovation capabilities.

\subsection{Potential Labour Shortages}

In the early stages of epidemic control, the movement of people was restricted and a large number of enterprises suspended production or delayed their opening. As the epidemic entered the normalization phase, logistics companies gradually resumed work and production, but they also had the important task of preventing a resurgence of the epidemic. Logistics companies are facing potential labor shortages due to inadequate human resource management planning and excessive staff turnover. Companies still have employment uncertainty and may face temporary labor shortages and job vacancies. This situation is also related to the lack of willingness of employees of certain logistics companies to return to work. Some employees choose to postpone their return to work in view of their health condition or the need to take care of their families. 


\subsection{Blocked Information Exchange and Inefficient Management}

So far, there are still some small and medium-sized logistics enterprises have not yet built a complete human resources information management platform, internal managers have not set up the awareness of online management, do not make full use of Internet information technology, the level of information technology is low, the management efficiency is not high.

After the outbreak of the epidemic, due to the inability of face-to-face communication between employees, information communication is hampered to a certain extent, and the traditional personnel management methods are subject to unprecedented challenges. Under this background, improving personnel management efficiency has become an inevitable choice for logistics enterprises. The timeliness of information exchange requires them to actively adapt to the new situation, take the initiative to establish and improve the human resources management information platform, optimize information communication methods, and seek new development. The widespread application of online information exchange platform can effectively alleviate the problem of communication obstruction, and the use of diversified software tools during epidemic prevention and control is conducive to the realization of logistics enterprises to strengthen personnel management, rapid notification, accurate delivery of information, efficient management mode, enhance the level of integrated management and crisis response capabilities.

\subsection{Imbalance between Supply and Demand of Logistics Professionals}

In recent years, China's logistics industry continues to develop, and the rapid growth of online business makes the industry scale continues to expand. The public safety and health emergencies are a wake-up call to the logistics industry. To survive for a long time, logistics enterprises must continue to transform and upgrade, high-quality and diversified demand for logistics personnel has also surged.

For the current existence of the imbalance between supply and demand of logistics personnel, we need to analyze from the perspective of both universities and enterprises. On the one hand, with the rise of logistics industry in recent years, colleges and universities have opened related majors, but due to the logistics belongs to the emerging industry, there is no related personnel training experience before, resulting in poor results of logistics personnel training. According to statistics from the China Federation of Logistics and Purchasing, China has more than 600 undergraduate colleges and 2000 middle and high vocational colleges and universities have opened logistics related professional courses, the number of students reached 500,000. However, the annual talent shortage in the logistics industry is as high as 600,000 , although there are universities and other educational institutions continue to send talents to the market, the logistics industry is still facing the problem of imbalance between supply and demand of 
talents. The universities do not understand what kind of talents are needed in the logistics industry, and there is no clear training plan. For the cultivation of technical talents often lack the most basic professional skills training and deeper level of innovation ability training; for academic talents, colleges and universities often ignore the ability to combine theory and practice training, resulting in academic talents are difficult to apply the theory to enterprise management, resulting in the lack of logistics professionals needed by enterprises. On the other hand, from the enterprise's point of view, logistics enterprises often lack the correct cognition for talent, not clear what kind of talent they need, the lack of long-term planning for talent team construction. Practice makes perfect, whether it is just graduated students, or already working employees, all need to sum up the experience in practice, improve their professional skills and innovation, so as to meet the rapid development of modern logistics industry on the need for logistics personnel.

\section{Recommendations and Insights}

The ever-changing social environment makes the survival of logistics enterprises difficult and crisis-ridden. The outbreak of epidemic to many logistics enterprises sounded a warning bell, in crisis situations, logistics enterprises must establish an emergency management system to improve their own risk tolerance, while the human resources department must also continue to reflect on upgrading, to provide important personnel protection for enterprise development.

\subsection{Establishment of the Crisis Response Leadership Team}

Organizational security in difficult times is particularly important. A systematic and global organization should be used to provide unified leadership and strong promotion. As an important member of the leadership team, the human resources worker, together with the company's top management, should take a series of strong measures to promote the company's strategic management and plan implementation. At this time, the person in charge of human resources should not only look at issues from the human resources perspective, but also consider how the company should develop from the company's perspective, strategic perspective and overall perspective. The crisis response leadership team is responsible for both implementing the human resource management program and directing the process of planning, organizing, and controlling the company's activities, as well as mobilizing the needed human, financial, and material resources. The work leadership team can refer to the idea of PDCA cycle (Daming ring) in guiding the implementation of the program, running a cycle according to the four processes of planning (Plan), execution (Do), inspection (Check), and processing (Act), and putting the unsolvable problems into the next cycle, so as to continuously improve the effect and quality in the cycle improvement process and effectively guarantee the human resource management program and the implementation. 


\subsection{HR Should Focus on Digitizing the Enterprise}

Digital construction refers to the use of new digital capabilities and technologies to accelerate business transformation and improve the efficiency of business model innovation, so as to maintain competitive advantage and promote enterprise development. Digital construction is now the focus of different enterprises in different industries, is an irreversible trend.

In addition to those on the front lines of logistics, the outbreak has forced the rest of the company's employees to opt for a new form of online office. Companies are going to use this epidemic to promote digital transformation on all fronts. Online recruitment, remote interviews, performance appraisals online talent development and other daily company activities are the present, not the future. Inefficient or even ineffective activities that consume a lot of human, financial and material resources can be accomplished through a strategic corporate digital transformation, allowing company employees to focus on activities that create more value for the business. Having a sound business information system is an important prerequisite for the smooth running of an online office. Many companies often choose to purchase external software systems to perform business information storage and exchange, but the external office system is not targeted to external development, and can only meet the basic office functions. In this case, enterprises must improve their information construction capabilities, investment in research and development for their own complete business information systems. As the staff deployment and coordination of human resources department, according to the online staff needs to provide timely advice to the enterprise R \& D department, to do a good job of human resources support to ensure the smooth progress of the online office.

\subsection{Promote Structural Change in the Company's Human Resources}

The HR department should seize this opportunity to promote structural reform of the company's human resources. Enterprises should allocate power to each decision-making level to authorize and motivate employees, reduce the management level, and expand the scope of management to promote organizational flat management, appropriate decentralization can reduce the barriers to information communication, improve enterprise responsiveness, to provide more information for decision-making and motivation of employees; functional integration is the people, things, institutions should have a role, the value of organic integration. And finally form a valuable and efficient whole, functional integration of people, things, institutions should be organic value of the role of the organic combination, improve the utilization rate and play a greater role. Integrating positions, eliminating meaningless positions, strengthening staff training, developing multi-faceted skills, and emphasizing the importance of multi-talented employees. 


\subsection{Human Resources Departments Should Coordinate People Well}

First of all, as an ad hoc team, the contingent HR team has the characteristics of a virtual team and works in a similar way to a virtual team. There are a lot of problems such as big cultural differences, low trust and isolation among team members, the HR department focuses on how to establish a team culture based on trust to help members overcome isolation, enhance trust level and improve communication efficiency. Measures that can be taken include: improving members' rapport through training and emergency rehearsal training; and holding discussions and meetings from time to time to enhance communication among members. In short, the human resources department should complete the preparation of relevant personnel to build a logistics team that can respond quickly.

Secondly, the epidemic has caused a considerable socio-economic impact, and against this severe background, the structural contradictions of recruitment and employment difficulties will gradually come to the fore after the epidemic, which will be a severe test for the human resources department. Effective organization of staff deployment as well as recruitment of new employees is the role and value of the human resources department. As the protagonist of employee deployment, the HR department quickly restores existing jobs and creates new ones. The first is to focus on migrant workers and flexible employees (mainly temporary and hourly workers) to solve part of the problem through transfer and deployment; the second is to intensify workforce skills training to adapt to the potential pick-up in employment demand after the epidemic stabilizes, and to use modern information tools to flexibly carry out distance training and employment guidance to provide good employment services.

\subsection{Multiple Efforts Are Needed to Solve the Talent Problem}

To solve the current imbalance between supply and demand of logistics talents, we need the joint efforts of universities and enterprises. First of all, communication between universities and logistics enterprises must be strengthened. Due to the lack of practical experience in colleges and universities, disconnected from the logistics talent market, so before opening the relevant professional courses, colleges and universities need to study the reality of the logistics industry and the future development trend, to understand the latest logistics talent market, including logistics enterprises on the talent cognitive ability, learning ability, professional skills and innovation ability requirements, according to the specific circumstances of the opening of relevant professional courses, and enhance the training of talents. Targeted to truly establish a talent training mechanism that is oriented to market demand (Pang, 2019).

The second is to cultivate the logistics industry's composite talents. With the rapid development of e-commerce and the continuous transformation and upgrading of the logistics industry, there is a computer, management, economy 
and other professional background of the demand for a comprehensive talent more and more, a single logistics personnel has been difficult to meet the market demand. This also requires the joint efforts of universities and enterprises, both sides need in-depth communication, integration of existing resources, not only through theoretical learning to enhance the professional knowledge of composite talents, but also through the practice of enterprises to enhance their practical ability to work, so as to cultivate a real composite talent.

\section{Conclusion}

After the epidemic, the logistics industry will usher in new opportunities for development and will also face a new round of challenges. How to survive and stand out in the fierce competition is an issue that every logistics company must consider. And human resource management as an important content of the internal management of the enterprise, more attention should be paid to it. Logistics enterprises must establish advanced human resources management concept, and constantly improve human resources management methods, in order to make the enterprise more long-term.

\section{Conflicts of Interest}

The authors declare no conflicts of interest regarding the publication of this paper.

\section{References}

Gao, Y. (2010). Research on Human Resource Management in Health Emergencies in Public Health Emergencies: Chongqing City as a Case Study. M.A. Thesis, Chongqing: Chongqing University.

Henan Business Daily (2020). Logistics Enterprises under the Epidemic: More Than 94\% of Enterprises Are Willing to Join the National Emergency Logistics Service System. https://baijiahao.baidu.com/s?id=1660184901136841994

Jiang, Z. Q. (2007). Human Resource Management in the Era of Knowledge Economy. Shanghai, IL: Shanghai People's Publishing House.

Knowing (2020). What the HR Industry Can Do in the Face of the Epidemic. https://zhuanlan.zhihu.com/p/106648199?utm_source=wechat_timeline

Pang, B. (2019). Cracking the Talent Problem Requires the Cooperation of Many Parties. China Logistics and Procurement, 10, 15-16.

Xi'an Daily (2020). These Logistics Companies Are Taking Action against Epidemic and Supply. https://baijiahao.baidu.com/s?id=1661141712528456166 